medical graduates (IMGs) were allowed to apply in the first round; I02 Quebec IMGs applied and 45 were matched, 26 of these in family medicine.

After round one, 98 applicants remained unmatched, and will try again in the second round on April 3. In that round, Ontario-based IMGs will be allowed, for the first time, to complete for placement along with other IMGs from across Canada. Banner says more than Iooo IMGs will compete in the second round.

Of note in round one is a continuing rise since 2003 in interest in family medicine; $30 \%$ of applicants selected it as their first choice in 2006, up from $27 \%$ the previous year. Banner says the College of Family PHysicians of Canada (CFPC) has been working with Health Canada on 2 programs to promote family practice among medical students.

Dr. Paul Rainsberry of the CFPC says he thinks the low numbers are due to "universities unconsciously undervaluing" this area of health care. He sees the programs as "an opportunity to try to give students a clearer sense of what family medicine is all about."

It seems to be paying off. "It's a small trend," Banner says, "but we're inching along." - Andréa Ventimiglia, Ottawa

DOI:IO.I503/cmaj.o6o304

\section{Manitoba pharmacists'}

\section{association clarifies Plan B}

\section{regulations}

A fter meeting with the Manitoba government official responsible for privacy, the Manitoba Pharmaceutical Association is reminding its members that women requesting the levonorgestrol (Plan B) morning-after pill have the right to remain anonymous.

In a Feb. 2 notice to pharmacy managers and a "Commentary" released jointly with Manitoba's Ombudsman, the association points out that Schedule 2 medication like levonorgestrol "does not require that a pharmacist record individuals' personal health information."
In April 2005, the association, along with other provincial associations, distributed the Canadian Pharmacists Association's (CPhA) program on levonorgestrol to its members. That program included a screening form to record sensitive personal information, such as the names and addresses of women wishing to purchase levonorgestrol.

A news article last year ( $C M A J$ 2005; I73:I435-6) revealed that many pharmacists across the country were requesting and storing that information before dispensing the drug, posing a potential barrier to access.

In a meeting between Manitoba Ombudsman Irene Hill and the association's registrar, "We talked about the current situation and what we could do to clarify that," Hill said. During the meeting, she said she emphasized that personal information should not be collected unless absolutely necessary. Other than the need to collect names and addresses for insurance purposes, "there's no requirement for the information to be collected." The joint commentary reflects this stand.

Ontario's Privacy Commissioner also met with the pharmacists' regulatory body in that province in early December 2005. The Ontario association quickly developed new guidelines and instructed its members not to use the $\mathrm{CPhA}$ screening form.

The Manitoba association believes its documents were clear to begin with on the issue of pharmacists asking for this information, says Ron Guse, the registrar. "Our position is that the pharmacist may need that information, but the patient doesn't have to supply it."

Nor does the pharmacist have to dispense the medication, he added. The Winnipeg Free Press has reported that women in Steinbach, Man., have limited access to pharmacies that dispense levonorgestrol. Two pharmacies in Steinbach refused to dispense levonorgestrol when a Free Press reporter declined to answer screening questions.

If pharmacists are not going to provide the medication, "they need to provide information for the woman seeking it" on how to get it, says Hill.

In Massachusetts, the state's pharmacy board upheld the complaint of 3 women who sued Wal-Mart Inc. for refusing to stock and sell levonorgestrol in its 48 pharmacies. Their suit argued that the retail chain violated a Massachusetts' law that requires pharmacies to stock all "commonly prescribed medications."

In response to the suit, Wal-Mart had said that it has a corporate policy of declining to carry emergency contraception. Following the ruling, a spokesman said the company would comply.

Wal-Mart Canada Corp. in Mississauga did not respond to repeated calls requesting an interview about whether they stock levonorgestrol in the Canadian stores. - Laura Eggertson, CMAJ

DOI:Io.I503/cmaj.060303

\section{News @ a glance}

Generic act: By summer, Médecins Sans Frontières (MSF) hopes to be able to ship the first order for an AIDS drug manufactured under a new Canadian law, known as the Jean Chretien Pledge to Africa Act. The 2004 Act allows for production of generic versions of drugs that are still under patent but are needed to address public health emergencies. The drug, being developed by Apotex Inc., is a fixed dose

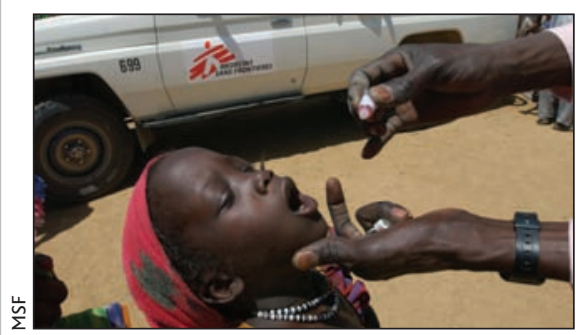

combination, a one-a-day AIDS antiretroviral that combines 3 patented drugs. It must be approved by Health Canada and then licensed by the patent holders, either voluntarily or through a compulsory licensing process. MSF was one of several organizations that lobbied for the law, but the only one with extensive operations in the field, which is why it placed the first order, explains Rachel Kiddell Monroe, MSF's Access campaign officer. "We are really hoping this order will open the floodgates, says Kiddell Monroe. "People need this drug, it can be a godsend. When the Canadian approval process is complete, the drug will also go to the World Health Organization for 
pre-qualification approval, which will ease its acceptance into many countries. - Ann Silversides, Toronto

Corruption in health care: Theft, bribery and extortion robs millions of health care dollars each year while deaths are caused by counterfeit drug use, drug-resistant disease and inability to pay bribes, finds the Global Corruption Report 2006. Transparency International (www.transparency.org), the German anticorruption body that released the report, states that each year at least $5 \%$ of the US\$3 trillion spent on health services worldwide are lost to corruption. In countries such as Ghana, surveys have found that up to $80 \%$ of nonsalary funds do not reach health facilities, with most leakage occurring between central government and the district. While in other countries such as Azerbaijan, informal payments from patients to doctors account for more than $80 \%$ of total health expenditure. The report also questions other spheres of influence such as pharmaceutical company lobbyists' impact on policy and doctors' decision-making. Measures to prevent corruption are possible: tighter control measures in the UK have saved US $\$ 300$ million since I999 by preventing fraud and pricing gambits. Sally Murray, Ottawa

DOI:I0.1503/cmaj.060333

Pulse

\section{Happy doctors? Satisfaction} with professional life

\section{$\mathrm{T}$}

he results of the $2004 \mathrm{CFPC} /$ CMA/RCPSC National Physician Survey regarding respondents' satisfaction with their current professional life held some surprises. For example, geriatricians surveyed were among the top ro most satisfied specialist groups, and diagnostic radiologists were among the bottom Io (Fig. I). Still, many popular conceptions were found to be true: specialties that many might consider to have better lifestyles (i.e., better work hours and lighter on-call schedules), such as dermatology, physiatry and psychiatry, were near the top of the list, whereas specialties with poorer lifestyles, such as family medicine and general surgery, were closer to the bottom.

These survey results might interest medical students as they try to decide which career path to follow. Furthermore, it might be worthwhile for the specialties closer to the bottom of the list to examine more closely the reasons for the lower satisfaction rates within their fields.

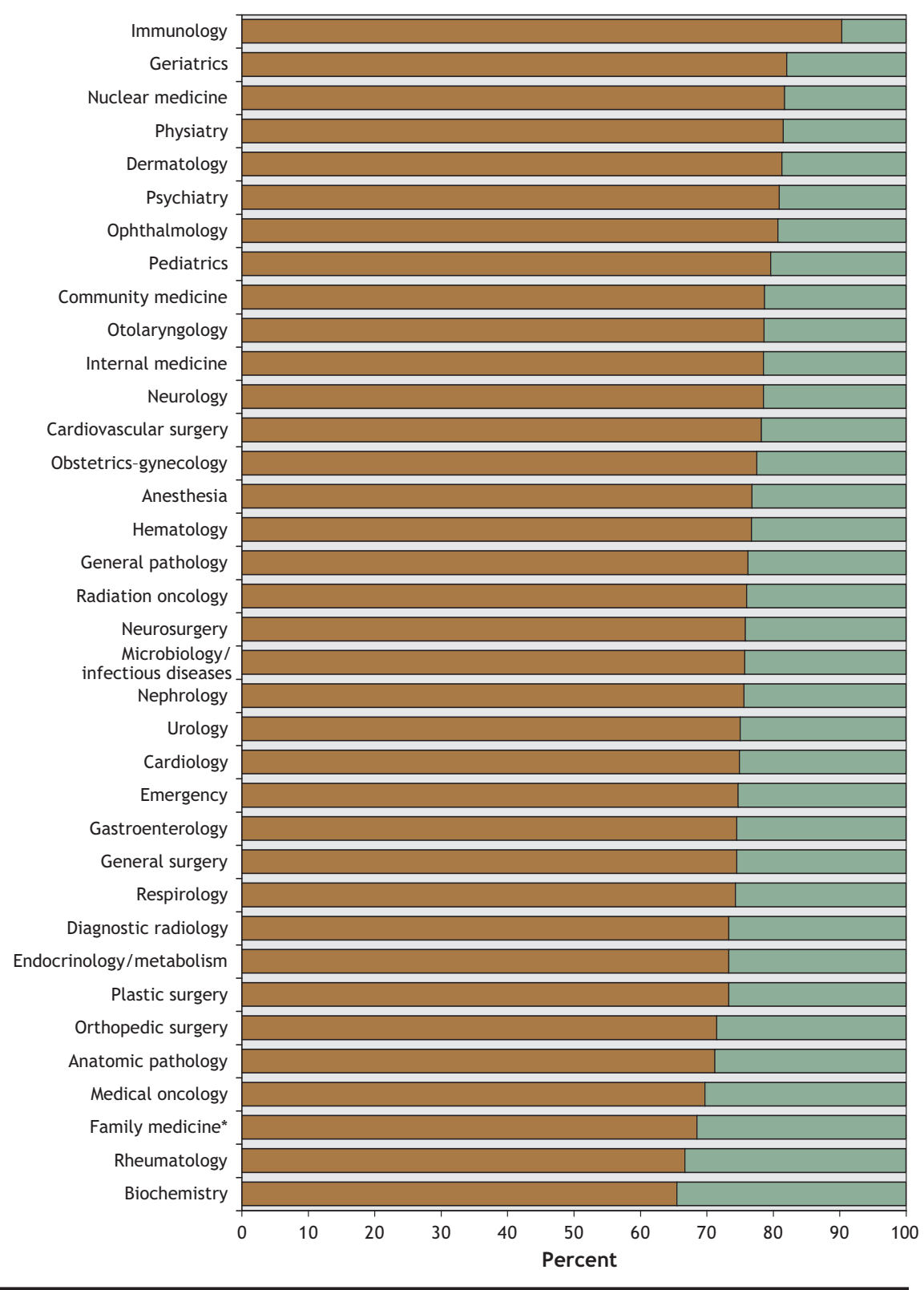

Fig. 1: Degree of satisfaction with current professional life. Brown bars represent physicians who were very or somewhat satisfied; green bars represent those who were neutral about or were somewhat or very dissatisfied with their current professional life. Source: 2004 CFPC/CMA/RCPSC National Physician Survey. *Includes CCFP and nonCCFP family physicians.
Despite previous reports that physicians are an unhappy group (CMA) 2003;I68[6]75I-2), the results show that the majority of Canada's physicians are satisfied to some degree with their current professional life, with as many as $65.5 \%$ of physicians in the lowest ranked specialty (biochemistry) stating that they were at least "somewhat satisfied." - Mark O. Baerlocher, Toronto

DOI:I0.I503/cmaj.05I405 